\title{
What Can Students Tell Us about "Skill- Building" in Canadian Writing Studies?
}

Christopher Eaton

University of Toronto Mississauga

The writing as a skill narrative permeates many post-secondary institutions and is increasingly prominent in conversations about Canadian writing studies. Most of us working in the field have encountered the notion that writing is a skill that can be learned once and for all, a common narrative that affects institutional and administrative decisions about writing initiatives and programming. Recent discussions in the Canadian writing studies community have challenged this narrative, with calls ranging from increased emphasis on writing as a social process, to questions about how we may disrupt the skills narrative, to research that helps dismantle the narrative altogether.

Although the desire to reject the skills narrative is understandable, it may also be an unrealistic goal in the current environment. Skills-oriented pedagogies and process-oriented pedagogies may always be in tension, but that does not mean that a more balanced discussion between the two cannot be achieved. Instead, it may be more prudent to scrutinize how skills-oriented pedagogies and process-oriented pedagogies impact teaching practices. Scrutinizing the tension between the two approaches in the classroom may allow writing studies practitioners to provide stronger arguments for the role that each element (process and skills) plays in our practice. By gaining a better understanding of this tension, we may be able to better articulate what we do and how it impacts our students.

This argument derives from research that I conducted with ten former students about their experiences with writing in our first-year writing course at a large Ontario college. During our discussions, we experienced conflicting narratives about the value of the writing instruction and about how students learned best in our first-year writing classroom. In one of these narratives, participants emphasized how much they learned through our scaffolded research paper because of the opportunity to receive feedback and integrate it in subsequent drafts of their work; they could experiment in a low-stakes environment and engage in an iterative feedback process. But many 
Volume 30, 2020

http://journals.sfu.ca/cjsdw

participants also highlighted how the smaller skill-building units often helped their understanding of the larger writing processes that they engaged in throughout the class and beyond.

This paper interrogates these seemingly conflicting narratives to generate a better understanding of the role that these elements play in writing studies pedagogy. It will begin by situating the wider skills narrative that we experience here in Canada in relation to the first-year writing course that I taught. Then, the student narratives will be analyzed through a narrative lens that invites students to participate as co-constructors of knowledge in research. From this analysis, the paper will transition to reflect upon what these two seemingly conflicting narratives might mean for the way we consider and discuss skill-building narratives in writing studies, particularly at the first-year level.

\section{The Skills Narrative in Canada}

The consequences of the skills narrative for Canadian writing studies has been a major conversation topic in recent years. Many discussions scrutinize how, as a writing studies community, we have contributed to the marginalization of writing studies in our institutions by accommodating administrative desires for "quick fix" workshops, one-off writing camps and courses, and singular classroom presentations. While these initiatives have their merits, Giltrow (2016) discussed how they work against our attempts to establish disciplinary status within institutions because they adhere to an overarching skill-building narrative (Bryant, 2017) that contradicts the processoriented and socially-situated complexity of writing and writing pedagogy. Paré (2017) argued that "we in Canada have, by and large, failed to convince university administrators and colleagues in the disciplines of the essential value of our work, and we need to ask ourselves why that is so" (p. 2). He called for arguments which draw upon both research and practice to support our claims about writing as well as supporting "claims for the efficacy of our teaching and tutoring with evidence that will sway budget-conscious administrators and dismissive colleagues" (p. 6). The skills narrative hinders pedagogy and student growth. It seems that it is also a central factor in writing studies' status (or lack thereof) in Canadian post-secondary institutions. To benefit from the little funding and few opportunities that we have, such as teaching first-year writing classes or running one-off workshops, those working in writing studies must adhere to the skills-oriented agendas that allow this funding to exist. The more that writing studies teachers adhere to the narrative, however, the more engrained it becomes in our institutions.

It seems like an impossible situation: the "skilling" mindset that opens spaces for writing pedagogy simultaneously hinders this pedagogy from taking root in the way that best practices (such 
as process, context, and iteration) require. The impact of this tension is best explained in Landry (2016), whose respondents indicated that "institutions want students to write effectively, but they do not want to support 'the teaching and research that would ensure this.' If writing instruction is perceived as a quick fix, if it is decontextualized and not informed by research, then it will continue to be ineffective" (p. 216). The skills narrative promotes a desire for quick-fix writing approaches that cannot accomplish the transformation in mindset that is required for students to develop writing strategies that will work long-term.

In this sense, it is logical that we seek ways to resist the skills narrative to advocate for better resources, better funding, and better opportunities that will allow us to move beyond skills. Bryant (2017) established a series of questions aimed to promote research that may overcome the skills narrative, asserting that "we as a research community [must] engage in empirical work that can begin to interrupt this dominant narrative of writing that permeates so many corners of the university context" (p. 16). Echoing Bryant and Graves (1994), Klostermann (2017) argued that we must move away from the idea of writing as something that can be learned once and for all. Both Bryant and Klostermann promote a shift towards writing pedagogy that focuses on writing as a socially situated process, which is supported by a wide array of writing studies literature (e.g., Badenhorst et al., 2015; Paré, 2009; White, 2006).

\section{Is Resistance Futile?}

It is unclear how this dismantling of the skills narrative can be accomplished or how meaningful change may occur. The desire exists among teachers and scholars who understand the benefits of process and iteration. The challenge is that the skills narrative has long been entrenched in postsecondary institutions, especially when it comes to writing pedagogy. As much as writing as a social process has deep roots in the literature, it has not taken hold in wider institutional circles, where budgets and funding are often linked to the tangible "skill-building" that occurs through writing instruction. Despite our knowledge of genre as rhetorical and social action (Freedman, 1994; Miller, 1984; Reiff \& Bawarshi, 2011), the skills narrative still dominates. Seeing writing as a social practice may have "thoroughly challenged this view of the writer and writing" (Bawarshi, 2003, p. 5) by emphasizing less about writer cognition and more about the social actions writers engage in when they write, but this knowledge has been primarily limited to the genre and writing studies scholarly/pedagogical communities. These ideas may benefit our pedagogy, but they have not really diminished the skills narrative that impacts how this pedagogy occurs. 
There is also the irony that writing studies benefits from the skills narrative. Although I have already touched upon this briefly, it is worth exploring this irony more deeply to show how difficult it is to dismantle the skills narrative. As historical studies by Russell (2002) and Skinnell (2016) have shown, institutions have often turned to composition/writing pedagogy to attract more funding and to respond to public demands for improved literacy skills. These appeals usually follow an increase in the number of people pursuing post-secondary studies (such as when Baby Boomers entered postsecondary studies) and situations where government funds promote initiatives to increase literacy (as the G. I. Bill in America did following WWII). Institutions have also used composition to earn accreditation. As both Russell and Skinnell demonstrated, institutions like Harvard and the University of Kansas used composition as a primary pillar to gain university status back when they were designated colleges. If they could show that they were teaching students vital writing and literacy skills, they could enhance their case for increased funding and status. As the demand for better writing and literacy skills increases, so too does the funding available for writing programming.

\section{Turning Challenge into Opportunity}

Writing studies and the skills narrative are closely related, which makes dismantling the narrative difficult. We may not like the skills model, but we benefit from institutional, public, and administrative desires to demonstrate the value of post-secondary studies through the tangible skills that students learn, such as writing. As Landry (2016) highlighted, there seems to be increased recognition for Canadian writing studies as a field, but budgetary restrictions, the desire for quick-fix writing solutions, and marginalization still hinder our work. Given the increase in students who attend post-secondary institutions (especially the growing number of international students who pursue studies in Canada) and the neoliberal thinking that influences budgets, this paradox makes sense. There is a desire for writing pedagogy, but it seems that this desire can be limited to how this pedagogy benefits institutional reports and evaluation metrics.

It seems that the skills narrative will not go away, and there will likely always be a tension between the institutional desire for measurable skills and the writing community's emphasis on processoriented writing pedagogies. The challenge is that the institutional conversation has been unbalanced, with the skills approach dominating. Perhaps, instead of dismantling the skills narrative, it may be more prudent to find ways that the conversation can become more balanced. It may be more useful to become comfortable working within this tension to understand how it impacts our 
Volume 30, 2020

http://journals.sfu.ca/cjsdw

pedagogy and student learning. Instead of seeing the narratives as necessarily conflicting, we in the writing studies communities may benefit from scrutinizing how they both influence our classrooms and contribute to student knowledge making.

\section{The Place}

I came to this position from research that I conducted with ten former students who took my firstyear college writing course. I taught this course for five years as a contingent faculty member between 2016 and 2020. I would teach 3-4 sections per semester (8-9 sections per year) with approximately 25 students per section. The course used a syllabus that extended across many sections and programs, simplifying the process for various instructors-many of whom taught on contract like myself-to teach the course. There were a few areas where instructors could assign a reading or activity to suit the discipline to which they taught, but the assignments, rubrics, and weekly subjects were fixed.

When I conducted this research in 2018-2019 (my third and fourth years teaching this course), the course had the following major assignment structure: a summary of an article (1 page), an analytical paper (2-3 pages), a persuasive paper (2-3 pages), and a final research paper completed in three parts (a proposal, an outline, and the paper). The course also required that students complete various quizzes to demonstrate that they understood particular skills that the course targeted, such as punctuation, citations, library searches, passive/active voice, subject/verb agreement, and parts of speech. The course was capped off with a final assessment worth $10 \%$ of the final grade.

As the assignment list demonstrates, there was a lot of material to cover in a fourteen-week semester. As an instructor, I often found that I was teaching skills as atomized units; I was teaching students to manage one quiz concept after another. This was especially true during the first $2 / 3$ of the semester when students completed the majority of their quizzes and the smaller writing assignments. When the students did get to write their article summary and the two smaller papers at the start of the semester, the fixed rubrics made it easy for me to quickly grade papers by checking boxes. However, the nature of my contract and workload made it difficult to provide substantial feedback to help students build as part of the process rather than just complete the assignment for the grade.

The real pedagogical value, I felt, came during the final project. The scaffolded nature of this project allowed the students to slowly build through the feedback they received on previous parts of the assignment. At this point in the semester, I could focus on providing substantive feedback because 
Volume 30, 2020

http://journals.sfu.ca/cjsdw

the course didn't have so many quizzes or smaller assignments demanding time and attention. There seemed a distinct break between the skills-oriented nature of the first nine weeks and the final five where we dealt with the final project.

The issue was that there didn't seem to be enough of this dialogic, process-oriented work. In my own teaching, I experienced the tension between skill-building and process writing, and I focused on the imbalanced way they came together in this course. The course seemed to prioritize checking boxes of atomized skills over developing student writing over time. I found myself wanting more scaffolded projects and fewer quizzes. I questioned what the students were getting from the moments where I taught from concept to concept rather than teaching the writing process itself. I wondered whether students were actually developing their writing skills or just keeping up. I wasn't sure if I was helping students or just getting them through their first-year writing requirement.

Before this project, my attitude towards the skills narrative was influenced by many of the prominent discussions in our Canadian writing studies community about skill-building and our marginalization in many post-secondary institutions. I tended, like many in our circles, to resist or at least lament the prominence of skill-building discussions that surround writing pedagogies, particularly at the first-year level. My negativity was exacerbated by the environment in which I taught first-year writing, where the program seemed to prioritize atomized skill-building. Many days felt as though I were teaching a service course that, to quote North (1987), amounted to doing "academic dirty work" (p. 13) rather than helping students build meaningfully through the writing process.

\section{Working with Students}

I wanted to understand how the course was helping students develop their writing. Specifically, I wanted to know what elements of the course allowed students to build their writing toolkit. Did they, like me, dismiss the more skills-oriented and quiz-oriented components of the course as little more than items they needed to complete for the grade? Did they see the same value in the scaffolded final paper that I did, or was I overestimating the value of feedback and the writing process despite all the literature touting its merits?

To explore these questions, I invited my former students to participate in research that reflected on their experience in the course. The course outline and interactions with colleagues often pointed to things that students should be able to do by the end of the course, what they do and how they react to certain elements of the course, and what each unit does for students. What often gets left out of 
Volume 30, 2020

http://journals.sfu.ca/cjsdw

these conversations is what the students actually learn and what units resonate most with them. As Klostermann (2017) argued, Canadian writing studies scholars need to better acknowledge the role of "students as knowers and contributors" (p. 21) in our research and teaching. Students hold a unique position as the primary stakeholders in the work that we do, but they are often outsiders to the process of how this work is developed for them.

\section{Critical Narrative Inquiry}

For this reason, I opted to work with former students because they not only had completed the course, but they also knew how their learning in our course impacted their work in other courses as they advanced through their various programs. In total, ten students joined the project, which made it ideal to delve deeply into their experiences in the course and to analyze how the course impacted their writing skills.

Because the project centred on narratives of student experiences in relation to teaching and learning in the first-year writing classroom, I opted to use Critical Narrative Inquiry (CNI) as a methodological and analytical framework. CNI focuses on the socially situated nature of learning as it relates to narratives of experience (Horan, 2013; Kim, 2016), which allows researchers to understand people's stories in terms of their larger social and educational practices. For writing studies, this lens allows researchers to see that writing and writing pedagogy are not something that happen only in the classroom, but rather are multifaceted endeavours that incorporate students' previous experiences, experiences which inform how they write, how they adapt to new written genres, how they engage with classroom teaching, and how they ultimately enact this pedagogy beyond the classroom as they learn new approaches to writing.

This lens established a baseline for the first stage of the research project: the first individual interview. This one-hour interview was used to trace participant experiences with writing more generally. I asked the participants about their writing before coming to college, about their writing in our course, and their writing since moving into their disciplines. This interview helped to situate participant responses in their wider writing experiences. Clandinin and Connelly (2000) discussed how CNI derives from narratives that are developed from fragments of many "storied moments of time and space, and reflected upon and understood in terms of narrative unities and discontinuities" (p.17). A narrative of experience represents a reflection upon many lived experiences that occurred at various times and places in the participants' lives. The participants' reflections upon, reactions to, and learning in our first-year writing class were influenced by their previous experiences writing. 
Volume 30, 2020

http://journals.sfu.ca/cjsdw

Their responses at various stages of the project were simultaneously influenced by their participation and interactions during the research and their experiences with writing in their programs. This initial interview helped to position these various facets of individual experience to provide context for the participants' responses.

Once the initial interviews were transcribed and coded for thematic links, the common ideas that emerged from these interviews were used to prompt deeper, more analytical discussions during the next stage of the project, in which students participated in a two-hour focus group. This focus group allowed participants to discuss several common ideas they shared in their first interview and to gain a better understanding of how these ideas compared when they were scrutinized from different perspectives. This stage of the project also gave us all time to examine such course documents as the assignment structures/parameters, the assignment rubrics, the syllabus, and the learning objectives. Many of the focus group activities and conversations developed at the intersection between the thematic ideas and the documents, with the former informing the analysis of the latter.

\section{Co-Constructing Knowledge: An Analytical Framework}

After this, the "critical" component of narrative inquiry became crucial to understanding and interpreting the participants' responses. Narratives of human experience cannot be considered knowledge in themselves. As Journet (2012) highlighted, writing studies research too often assumes that narratives, particularly student narratives, are an accurate representation of the truth. Journet contested that "personal narratives in composition are not inherently more authentic than other research modes" (p. 17), and asked "by what criteria do we evaluate personal narratives in order to determine how 'truthful' or 'correct' they are" (p. 19). The individual interviews and the focus groups provided a wealth of ideas, but they represented only a version of the truth that captured a particular experience at a particular moment in time (see Clandinin, 2013). What was needed was a framework wherein the analysis of these narratives could become more critical than simply the surface answers, more dialogic and collaborative such that several voices could contribute to knowledge building. The final narrative and analysis still represent a version of the truth, but the proper framework could ensure a more robust interpretation of that truth that could produce stronger, more expansive reflections that derived from collaboration.

CNI allows such a framework since it is a reflexive (Kim, 2016) and "relational process" which "gives rise to stories about self and the world" (Gergen \& Gergen, 2011, p. 379). Narratives do not arise from a single participant recounting their experience. The narratives arise from the interactions 
Volume 30, 2020

http://journals.sfu.ca/cjsdw

that the participants have with the interviewer and the questions asked. In this project, they also arose from the previous relationship that participants had with me (as their former instructor) and their interactions with other participants during the focus groups. Analyzing their responses, therefore, involved "a form of negotiation and active participation in social discourse $s$ a way of constructing new social discourses" (Striano, 2012, p. 153). Through active participation in the analysis, participants could develop and redevelop their ideas and versions of the narrative at various stages of the research process. Early in the project, this happened more implicitly as participants continued to reflect upon their experiences after the initial interview, as they interacted during the focus group, and as they experienced new writing situations in their courses.

During the third and final stage of the project, this negotiation and participation became more overt. After the initial interview and focus group, I developed a preliminary narrative for each participant. This narrative was framed around an analysis of their responses to that point in our interactions. After this narrative was developed, I sent it to the participants to review. We then met to discuss the narratives, and we used this meeting (approximately two hours) to examine the narratives and scrutinize the analyses. The participants had an opportunity to redevelop or revise any version of the analysis. I also asked them questions about particular analytical points in the narrative to clarify elements or develop them more extensively. Together, the participants and I reshaped their narratives and expanded the analyses. Rather than having a single interpreter of human experience, the research process became more relational and co-constructive.

While some of these discussions and changes were made in the narratives themselves, the coconstruction of ideas also expanded into the fourth stage, a second individual interview. The participants and I would use the analytical discussions of the narrative to reflect upon their other experiences with writing both before and after the course. The result was another opportunity to scrutinize their responses from the initial interview and focus group. The participants were doing what Harvey (2015) called going beyond member checking to actively participate in the analytical process. The analysis was a collective experience wherein every participant had a chance to contribute to the knowledge building process that derived from their narratives.

\section{What the Students Said}

"I Didn't See Myself Changing"

One of the most prominent threads that emerged in our initial interviews was that most participants resisted the course at first. They came to our class with negative outlooks on "English" classes and 
Volume 30, 2020

http://journals.sfu.ca/cjsdw

struggled to see how the class would offer them something that hadn't been covered in their previous experiences. Many had experienced four years of high school English and saw a college writing class as an repetition of that work. One participant, Kristen, lamented how she "had just done four years of English-I was so tired of it." She explained that, after her high school experience, "I didn't see myself changing" at the college level. Kristen did not see the class as an opportunity to develop her writing because she did not believe that she had grown in high school.

Other participants, like John, noted that they were anxious about taking the class because they always struggled with the subject. He described how "[English] was the only course that I took at university level that I was never confident that I could perform at that level." He struggled throughout high school and in his first post-secondary program in technical writing. Typically, he required tutoring to support his journey through English. Every time he had to take another course, he would dread it, thinking "it's that time again." As a result, his initial impulse coming into a first-year writing class was to drop the course and find something else. He explained that it took several weeks of seeing how different the course was from his other ventures with writing classes, coupled with some coercion from his friends, to convince him to stay.

Other students had an emotional reaction to the class. Clara explained how "some people really do believe that they thought it would be a waste of time...I thought it was going to be a waste of my time." Clara came to the program with extensive work and educational experience, having already completed an MSc, albeit in a program that did not require much academic writing. Still, a first-year writing course may have seemed elementary to her, and her sentiments were shared by many participants who struggled to engage fully in a course that was not directly associated with their program but that still demanded significant time and energy. The result was that students often had an emotional reaction to the course that hindered their ability to get on board with the teacher or programmatic curriculum at first, regardless of the design.

Many students struggled to overcome their previous experiences and conceptions of writing. Some, like John, thought they could not grasp the course concepts. Others, like Kristen and Clara, thought that this writing course would repeat the concepts that they had already covered. They saw little opportunity for growth. In all three cases, ours was a milestone course that they had to complete but did not want to engage with. They needed the credit to satisfy institutional requirements and then they could move on. 
Volume 30, 2020

http://journals.sfu.ca/cjsdw

\section{Offer Something Different}

One thread that emerged alongside their initial resistance was that they also started to engage more with the course once they saw that it offered them something different from what they had experienced before. The way that they would discuss their engagement increasing was typically in relation to the scaffolded research project. Every participant asserted how much they valued building their ideas over time with the support of constructive feedback. For many, this was something new that they had not encountered before, and they saw it as a primary learning process in our class.

The process allowed them to see their growth as writers. One participant, Kara, described this best. She, like many other participants, resisted the class initially, but eventually came to see herself growing through the process. When asked to describe the class, Kara characterized it as

essentially an English class. It has all the requirements and expectations of a previous course you have taken. The difference, however, is that it is taught to learn instead of taught to test-it focuses on improvement rather than getting a mark... [it] is more like do what you can. You started here. I want to see you grow more. I want to see you get better.

Kara is referencing our final project in which students complete a proposal, a draft or outline (their choice), engage in peer review, and submit a final paper on a topic of their choosing. For Kara, the scaffolded nature of the assignments, where projects had numerous rounds of feedback and redesign, helped her to "engage with writing in a way that [she] never had before." The focus was on the ideas and developing them according to her own style rather than accommodating some prescribed template for a grade as she had to do in high school. This allowed her to overcome her barriers to learning and engaging in this process. Instead, she could focus on growing as a writer through each stage of the project.

\section{Feedback and Process}

Kara was not alone. Nine of ten participants cited feedback and process as the most essential macrolevel components that helped them develop their writing. Sam differed from the others, claiming that he focused on each assignment individually to master the genre conventions of a proposal or final research paper. But even Sam considered the feedback and writing process essential despite taking a different approach: "I was more motivated when I got the feedback. I was challenged a little bit and it gave me motivation to go deeper and actually get it right." Sam often claimed that he wanted to "get things right," namely to achieve a high grade by trying to perfect the genre in which he was writing. 
But, even though he considered each assignment as its own individual challenge and did not look at scaffolding the same way other participants did, he still saw the feedback that he received between assignments as an essential element to getting things "right" on subsequent assignments as he adjusted to new genre conventions.

The other participants all described the course as an opportunity to build their writing and communication through a process rather than writing something once for a grade. Victor, for example, discussed how he liked the

whole [writing] process. When I say the whole process, I mean having your ideas and having to filter down to the best ones, even if you think you have the best one, it's always good to have a second set of opinions...And just getting down and jotting those points, refining those ideas.

Victor alluded to the time and space to contemplate ideas that the scaffolded project offered. He had too many ideas to fit into one paper (don't we all?) but having the space to refine those ideas before writing allowed him to select the best ideas to make his argument. Victor highlighted how writing and critical thinking intersect. To develop a strong piece of writing and to engage in a strong writing process, Victor required space, time, and a second set of opinions to refine his ideas before putting them onto paper. Giving him this time maximized his learning experience in our class.

\section{Scaffolding: Taken-For-Granted}

Writing scholars understand that scaffolded writing, feedback, and process are essential elements to student growth. White (2006) framed repeated writing and feedback as best practices that most writing teachers could use. Lillis (2003) and Paxton and Frith (2014) have identified the dialogic feedback process as central elements of writing pedagogy. At conferences, it is common to pay lipservice to scaffolding and process orientation as if they were taken for granted as elements of our teaching. I have already acknowledged my own tendency to favour process-oriented writing pedagogies over the skills-based workshops that demanded so much time and attention in my classroom. My participants responses confirmed, at the very least, that the scaffolded writing process was one of the more beneficial elements of the course for them.

Yet I was surprised at how few participants had written in this way before our class, which made me question whether scaffolding and feedback were as commonly recognized as I and many others in writing studies assumed. Eight participants stated that they had not encountered this process in other writing classes. Victor was the only person who had engaged in similar processes before college. Another participant named Mark had had previous experience with post-secondary writing 
courses before coming to our writing class. Even exceptional students like Clara, who had a master's degree, did not have previous exposure to scaffolded writing assignments. Clara had written a bit for her food science community, but she struggled to expand her writing to suit larger audiences and other discourse communities.

Evidently, participants found scaffolded writing processes useful, but I wanted to know why they found this approach conducive to their learning. Trying to understand the role that scaffolding played for them became a primary concern for the focus group stage and the second interviews. In the focus group, Clara commented on how engaging in this process, receiving feedback, and developing her analysis were crucial for her to go from seeing the course as a waste of time to understanding its wider goals and how they applied to her writing:

It's not just college reading and writing. It had a different approach to developing my writing skills and analytical skills. The informal and formal feedback helped me shape my topic or idea into something that one would like to read. The structure of the course gave room to develop different skillsets in my writing.

She identified iteration and audience awareness as crucial elements of her growth. Having a course structure which allowed this gave her time to analyze her ideas and tailor them to different audiences. Even with her previous experience, she benefited from an introductory writing class because it offered her time, space, and direction to consider new genres.

These reflections were enhanced by the work that she did with Kara in the focus group. When they were asked to explain what other students can expect from this course, they both emphasized the role of feedback and process in helping them build upon what they already knew:

You go into the course with very low expectations, thinking this will be just another English class.

But it was more aimed at developing our writing style. The scaffolded structure was aimed to help us improve from our current writing ability. The way it [feedback] flows through all the topics helps you get the best final product.

Like Victor's comments about the writing process, Clara's and Kara's definition suggests that process, time, and feedback enable students to build upon the foundations they already have. Writing was complex and iterative, and this enabled them to grow as writers. There was more than just skillbuilding through a single unit; the skill-building happened over time and with significant collaboration.

Being able to show this through student reflections, particularly when those students were reluctant participants initially, can be useful to articulate the necessity for proper funding that allows 
time, space, and expertise to implement these processes. Comments from students like Victor, Clara, and Kara can help instructors demonstrate the value in scaffolding, feedback, and process. They articulate the value in having time to build their writing and develop their ideas to achieve a stronger writing style that is accessible to a wider range of audiences.

\section{Minutiae: The Other Side of the Narrative}

On the surface, this emphasis on scaffolded writing, feedback, and iteration is positive for writing studies and our arguments against the skills narrative. The students themselves confirm that what we scholars and teachers believe are the most important elements to writing pedagogy are indeed the elements that most help them learn. However, as we kept discussing the participants' experiences, a key tension arose. It was encouraging that our scaffolded writing project was central to helping students engage with the course and develop their writing, but, in reality, the project did not occur until the final weeks of the course. It may have been what was most memorable to participants, but it seemed unlikely that one project could account for them characterizing the learning that they did in the course as valuable and engaging, compared to the disdain that many of them had for the subject when they entered the classroom.

The more that we discussed the course in the focus groups, and the more we examined the narratives from the first interview, the more the participants questioned whether the scaffolded writing was as central to their learning as they previously imagined. The more that we scrutinized the course, the more the skill-building mechanisms that the course implemented in the early weeks came to the forefront of the conversation. As much as participants highlighted the scaffolded research process as central to their learning, they also emphasized the role of the basics that our class offered, such as grammar lessons, discussions about formatting, and units about incorporating references to strengthen arguments.

It was not until I spoke with my participants that I understood how these elements impacted their learning. Most of my participants had little grammar or stylistic instruction prior to college. Kent and Sam, for example, had never encountered instruction on formatting or conducting research. They explained that these elements were required in their other courses, but instructors in their disciplines assumed that students grasped these concepts because they were "basic." Without these lessons in our class, they would not have had this foundation that impacted projects in their disciplinary courses. 
Volume 30, 2020

http://journals.sfu.ca/cjsdw

Even students who had learned grammar in high school found it useful to go over these concepts again. During his second interview, Victor outlined how it was important to "go back and revisit basics before you get technical and things get difficult with each level. There was a very practical course delivery." For Victor, the minutiae built into the larger writing process. The practicality of these elements allowed him to give structure to the abstract ideas that he was writing. He valued the chance to work in smaller units and refresh his skills with more grammatical elements before writing more extensive research-oriented papers later in the course.

Practicality was equally emphasized during the focus group when John and Sam collaborated on defining the course. Their definition seemed to contradict the value that Kara and Clara placed on scaffolded writing in their own definition. Instead, John and Sam argued that "this course is designed to strengthen the ability of students' reading and writing. And to enhance their ability to write a professional research paper and develop practical skills such as learning tone, style, citations, and how to write with purpose." Their focus group discussion focused more on the minutiae than Clara and Kara did. John and Sam highlighted the final product, but they spent more time exploring how stylistics contributed to their learning. They emphasized the pragmatism associated with these smaller elements that allowed them to have a clearer understanding of the mechanics behind their writing. Taking time to emphasize these ideas helped them to develop the larger product because they understood why they wrote the way they did.

Process and feedback are integral elements to teaching writing. Smaller elements, such as grammar, research skills, and referencing, are easy to overlook as core components of first-year writing courses. To accommodate growing international student cohorts, the college implemented many of these basic elements, including grammar and citations, and increased emphasis on academic integrity as major components of the class. My class is the place where these lessons have been implemented so that students can have these basics before they move into their more advanced disciplinary work. These units are the "discrete skills and strategies" (Paré, 2017, p. 6) that can be frustrating for instructors and students alike. But they have value for students. The "basics," as Victor called them, build into the larger process. The elements that John and Sam described-tone, style, writing with purpose for a specific audience-derive from these smaller strategies that may seem menial at first. Students may not see the value of these lessons immediately, but, like Victor, John, and Sam, they can come to realize how these elements build into bigger concepts that they can implement in their own disciplinary and professional discourse communities. 
Volume 30, 2020

http://journals.sfu.ca/cjsdw

Are there other ways that these could be implemented as part of orientation? Perhaps. But it is more likely that first-year courses will continue to be handed these skills-based units that students must be taught. It is therefore useful to understand the value that these elements provide students and the knowledge that can be built. By giving students the tools to dissect the language, understand its components, and use this knowledge to develop a structurally sound paper, they receive more tools for building, thinking, and articulating their thoughts in a critical way, not just in the first-year writing classroom but also in their disciplinary coursework.

\section{Discussion and Conclusion}

I would like to end this paper by reflecting upon how skills-oriented pedagogies and process-oriented pedagogies impact teaching practices and how we in the writing studies community might think of these narratives that seem always to be in tension. It's true that responses from ten students from one course at an Ontario college won't revamp the way we think about the skills narrative. The discussions that I had with former students, however, have made me reflect on what skill-building might mean in my classrooms and the value that the elements I have so often mitigated/dismissed might play in student learning. This has led me to reconsider the way that the skills might impact my pedagogies and complement rather than restrain the writing process.

Negativity about skill-building seems to pervade many corners of Canadian writing studies, and I'll concede that I still struggle to come to terms with skill-building narratives even after reflecting with my former students. That said, my conversations with these students helped to reframe the way that I thought about the role of skill-building in first-year contexts. The scaffolded writing process is a primary learning tool, and, for many of my participants, it was the process that stood out the most as they reflected on their experiences in my course.

But this process was enhanced by many of the smaller units on grammar, syntax, formatting, and academic integrity. These smaller ideas built into the larger processes in ways that I had never considered before. For Victor, this meant revisiting core grammatical concepts that could help him express his thoughts as the papers became more complex. And as much as Clara and Kara emphasized scaffolding as central to their learning, students like John and Sam highlighted the role that stylistic elements played in helping them not only to develop their ideas in our class but to also meet the expectations of their other courses. It seems that, in this first-year context, atomizing certain skillscitations, syntax, grammar-was an important stage in the early parts of the course that allowed many students to develop more nuanced and complex papers in the latter stages of the course. These 
Volume 30, 2020

http://journals.sfu.ca/cjsdw

elements also gave students a foundation in certain "basics" that many of their other classes assumed they already knew.

Despite the reservations that still linger when I think of my teaching as "skill-building," I am more willing to explore the necessity of these elements. If students don't learn skills that may be considered the basics in my first-year writing class, will they be able to maximize their learning and writing when they do get to process-oriented writing? Student responses in this context offer a layer to begin scrutinizing how these pedagogies might work in unison rather than against each other. Student responses from other courses, particularly first-year classes at the university level where student demographics are different, contexts where a single syllabus doesn't span dozens of sections of the same course, first-year university classes, and contexts beyond the first year where students should already grasp the fundamentals, would offer new dimensions to understanding how the tension between skill and process plays out in Canadian writing studies.

Perhaps dismantling a skills narrative is not necessary or even desirable. Instead, it might be better to strive for a rebalanced narrative. It would be useful to achieve more balance where scaffolded pedagogies receive more prominent recognition. The writing-as-a-skill and writing-as-aprocess narratives may not be as antithetical as they seem. Perhaps instead of negating one narrative, we would benefit from understanding and showing how these varying pedagogical approaches can coincide to enhance both student learning and our pedagogies in the process.

\section{References}

Badenhorst, C., Moloney, C., Rosales, J., Dyer, J., \& Ru, L. (2015). Beyond deficit: Graduate student research-writing pedagogies. Teaching in Higher Education, 20(1), 1-11.

Barton, D., \& Hamilton, M. (2012). Local literacies: Reading and writing in one community. New York: Routledge.

Bawarshi, A. (2003). Genre and the invention of the writer: Reconsidering the place of invention in composition. Logan, UT: Utah State UP.

Bryant, K. (2017). Interrogating conflicting narratives of writing in the academy: A call for research. Canadian Journal for Studies in Discourse and Writing/Rédactologie, 27, 13-18.

Clandinin, D. J. (2013). Engaging in narrative inquiry. Walnut Creek, CA: Left Coast Press.

Clandinin, D. J., \& Connelly, F. M. (2000). Narrative inquiry: Experience and story in qualitative research. San Francisco, CA: Jossey-Bass. 
Volume 30, 2020

http://journals.sfu.ca/cjsdw

Freedman, A. (1994). 'Do as I say': The relationship between teaching and learning new genres. In A. Freedman \& P. Medway (Eds.), Genre and the New Rhetoric (pp. 191-210). New York, NY: Taylor \& Francis.

Gergen, K. J., \& Gergen, M. M. (2011). Narrative tensions: Perilous and productive. Narrative Inquiry, 21(2), 374-381.

Giltrow, J. (2016). Writing at the centre: A sketch of the Canadian history. Canadian journal for studies in discourse and writing/Rédactologie, 26, 11-24.

Graves, R. (1994). Writing instruction in Canadian universities. Winnipeg, MB: Inkshed Publications.

Horan, J. (2013). Words collide, mindsets remain: A journey of cross-cultural narrative inquiry. In S. Trahar (Ed.), Intertextualising Narrative Inquiry (pp. 179-194). New York, NY: Routledge.

Journet, D. (2012). Narrative turns in writing studies research. In L. Nickoson \& M. P. Sheridan (Eds.), Writing studies research in practice (pp. 13-24). Carbondale, IL: Southern Illinois UP.

Kim, J. H. (2016). Understanding narrative inquiry. Thousand Oaks, CA: Sage.

Klostermann, J. (2017). Writing on the ground. Canadian Journal for Studies in Discourse and Writing/Rédactologie, 27, 19-23.

Landry, D. L. (2016). Writing studies in Canada: A people's history (doctoral dissertation). Retrieved from UBC Open Library Collections. (DOI 10.14288/1.0308778)

Miller, C. R. (1984). Genre as social action. Quarterly Journal of Speech, 70, 151-167.

North, S. M. (1987). The making of knowledge in composition: Portrait of an emerging field. Portsmouth, NH: Boynton/Cook.

Paré, A. (2017). The once and future writing centre: A reflection and critique. Canadian Journal for Studies in Discourse and Writing/Rédactologie, 27, 1-8.

Paré, A. (2009). What we know about writing, and why it matters. Compendium 2: Writing, teaching, and learning in the university, 2(1), 1-7.

Paxton, M., \& Frith, V. (2014). Implications of academic literacies research for knowledge making and curriculum design. Higher Education: The International Journal of Higher Education and Educational Planning, 67(2), 171-182.

Reiff, M. J., \& Bawarshi, A. (2011). Tracing discursive resources: How students use prior genre knowledge to negotiate new writing contexts in first-year composition. Written Communication, $28(3), 312-337$. 
Volume 30, 2020

http://journals.sfu.ca/cjsdw

Russell, D. R. (2006). Historical Studies of Composition. In P. Smagorinsky (Ed.), Research on composition: Multiple perspectives on two decades of change (pp. 243-276). New York, NY: Teachers College Press.

Skinnell, R. (2016). Conceding composition: A crooked history of composition's institutional fortunes. Logan, UT: Utah State University Press.

Striano, M. (2012). Reconstructing narrative: A new paradigm for narrative research and practice. Narrative Inquiry, 22(1), 147-150.

White, E. M. (2006). Defining by assessing. In P. Sullivan \& H. Tinberg (Eds.), What is "college-level" writing? (pp. 243-266). Urbana, U.S.A.: National Council of Teachers of English. 